\title{
O ensino musical no reino de D. Pedro II anunciado em impressos periódicos: de 1840 a $1889^{1}$
}

\author{
Musical education in the reign of Dom Pedro II in newspapers: \\ from 1840 to 1889
}

\author{
Everton Vieira Barbosa ${ }^{2}$ \\ FABIANA Lopes DA CUNHA ${ }^{3}$
}

1 Este texto é uma revisão do artigo publicado nos Anais do I Simpósio Internacional Patrimônios: Cultura a Sociedade no século XXI.

2 Universidade Estadual Paulista (UNESP/Assis). E-mail: semusico@hotmail.com

3 Universidade Estadual Paulista (UNESP/Ourinhos).

E-mail: fabiana@ourinhos.unesp.br

\begin{abstract}
Desde a inserção no Brasil em 1808 e sua oficialização em 1821, a imprensa favoreceu a divulgação de informações no âmbito político, econômico, social e cultural. Dentre as notícias divulgadas no âmbito sociocultural, identificou-se, em alguns periódicos, os anúncios de diversos prestadores de serviço, em especial de professores de música. Atentos a esses anúncios, objetiva-se, com este trabalho, identificar as informações voltadas ao ensino musical, conhecendo seus agentes, os instrumentos executados, os valores cobrados e os locais de ensino musical. Tais informações contribuirão nos estudos voltados à música e à imprensa no Brasil, uma vez que os recursos para a gravação sonora inexistiam no país, mantendo a primeira dependente da segunda para ser divulgada e arquivada pelos músicos durante o segundo império.
\end{abstract}

Palavras-chave: imprensa brasileira, anúncios impressos, ensino musical.

From its insertion in Brazil in 1808, and your oficialization in 1821, the press favored the release of information in the politic, economic, social and cultural ambit. Among the released news in the socio-cultural ambit, we identify announcements from various service providers, in especial, music teachers, in some printed journals. Focusing on these announcements, this work aims to identify the information related to music education, knowing its agents, the performed instruments, the amounts charged and where these musical classes took place. Such information will contribute in the studies that focus on music and the press in Brazil, since sound recording resources didn't exist in the country at the time, music needed the prees, tobe released, filed and storaged by musicians during the second empire.

Keywords: Brazilian press; Print ads; Music education. 


\section{INTRODUÇÃO}

O início do ensino musical no Brasil não tem uma data precisa. Dentre os registros mais antigos, encontram-se as anotações de viagens de Jean de Léry (15361613) em Histoire d'um voyage fait em la terre du Brésil, escritas no ano de 1578 durante sua viagem entre março de 1557 e início de janeiro de 1558.

Em suas anotações, Léry (1578) registrou informações sobre a tribo Caraíba e os cantos e melodias musicais executados durante suas cerimônias. Se essa tribo já desenvolvia a prática musical em seus ritos, provavelmente o ensino musial entre eles já existia antes do contato indígena com o europeu.

Porém, mesmo com a existência do ensino musical entre os indígenas e durante o tempo colonial, percebe-se que sua intenção não era a mesma do ensino praticado pelos europeus em tempos de colônia ou em tempos de império.

Enquanto o ensino musical indígena tinha o intuito de transmitir o conhecimento entre as sucessivas gerações, mantendo sua cultura e ritualística, o ensino musical jesuíta voltado aos índios tinha a finalidade de introjetar a cultura cristã e, consequentemente, minar os ritos indígenas, considerados pagãos pelos jesuítas.

Ainda que as formas de ensino musical destacadas tenham o objetivo de manter uma tradição cultural, seja a indígena, seja a cristã europeia, ambas se diferiam do ensino musical durante o período imperial no século XIX, com a finalidade profissional e comercial.

Com a vinda da família real para o Brasil em 1808, muitos músicos que chegaram da Europa acabaram fazendo da antiga colônia portuguesa sua nova moradia, adaptando seu modo de vida a este novo espaço de sociabilidade. Um fator que possibilitou o desenvolvimento do ensino musical profissional foram os anúncios em impressos periódicos.

Autorizados desde 1808, porém censurados até 1821, os impressos eram restritos aos conteúdos políticos, econômicos e de informações internacionais, voltados aos interesses da coroa (ABREU, 2010).

Assim, com o fim da censura, os impressos já na década de 1820 multiplicaram seus assuntos, abordando temas voltados ao âmbito social e cultural. No âmbito cultural, a música se fez presente em comentários sobre os espaços em que seria executada, facilitando o contato dos leitores e ouvintes dos impressos nesses locais de sociabilidade.

\section{OBjetivos E Metodologia}

Durante o segundo reinado (1840-1889), que é o foco deste trabalho, os anúncios musicais são mais específicos, demonstrando uma provável consolidação do ensino musical na cidade do Rio de Janeiro.

Desse modo, com o objetivo de identificar, no ensino musical, alguns professores, instrumentos e locais de ensino na cidade do Rio de Janeiro desse período, analisaram-se os anúncios de alguns impressos periódicos, em especial do Almanak Administrativo Mercantil e Industrial do Rio de Faneiro ${ }^{4}$. Foi dada maior atenção a ele por abranger quase todo o período de governo de D. Pedro II e pelo grande número de informações musicais nele encontrados.

Para ilustrar a quantidade de anúncios de ensino musical na cidade do Rio de Janeiro, elaborou-se alguns gráficos indicando a quantidade de professores por ano, gênero, e pelos instrumentos ensinados ou indefinidos nos anúncios.

Além disso, explanaram-se brevemente alguns impressos periódicos que publicavam anúncios de instrumentos, métodos de ensino musical e de professor de música e aqueles voltados integralmente ao conhecimento musical.

\section{O Ensino musical no Rio de JANEIRo DURANTE O SEGUNDO REINADO}

Antes do início do segundo reinado, já apareciam informações sobre o ensino musical no Rio de Janeiro. Na 268 edição do fornal do Commercio (1838), por exemplo, foi publicado o seguinte anúncio:

RAFAEL Lucci, professor de piano e cantoria, sobrando-lhe ainda algumas horas para dar lições, o faz ciente às

4 Conhecido como Almanak Laemmert, por causa do sobrenome dos irmãos Eduardo e Henrique, este impresso era publicado anualmente no Rio de Janeiro na Tipografia Universal Laemmert. Atualmente ele está micro-filmado e digitalizado pela Fundação Biblioteca Nacional, disponível em: < http:// objdigital.bn.br/acervo_digital/div_periodicos/ almanak/ almanak.htm>. Acesso em 21/01/2016. Não foram obtidas informações sobre os anúncios de ensino musical no ano de 1846, que se encontra na página 249, segundo o índice, pois a partir da página 243 até a página 254, não está disponível o micro-filme nem a digitalização das mesmas. 
pessoas que quiserem utilizar-se do seu préstimo, podendo dirigirem-se ao beco dos Ferreiros n. 7, $2^{\circ}$ andar, perto da praia de D. Manoel (JORNAL DO COMMERCIO, 1838, p 04). ${ }^{5}$

Neste anúncio podem-se perceber informações importantes, como o nome do professor, o que ele ensinava, o local onde se poderia encontrá-lo e onde seriam ministradas as aulas, combinando os dias e os horários das aulas. Além de conter essas informações, poderia também ter outras falando sobre métodos de ensino ou prêmios musicais obtidos. Geralmente, nos avisos encontrados em outros periódicos, essas características permaneciam, uma vez que em alguns impressos cobravam pela quantidade de linhas, enquanto outros cobravam por todo o anúncio.

No caso do Almanak Laemmert, a cobrança por linha, geralmente no valor de $1 \$ 000$ réis, obrigou muitos professores(as) de música a limitarem as informações por eles(as) divulgadas, como o tipo de instrumento ensinado ou o endereço.

Abaixo, observa-se a quantidade de anúncios no Almanak Laemmert separados por anos e por gêneros. Devido à grande quantidade de avisos elencados, optou-se por separar as informações por década:

Gráfico 1. Anúncio de Professores de música (1844-1849), exceto o ano de 1846.

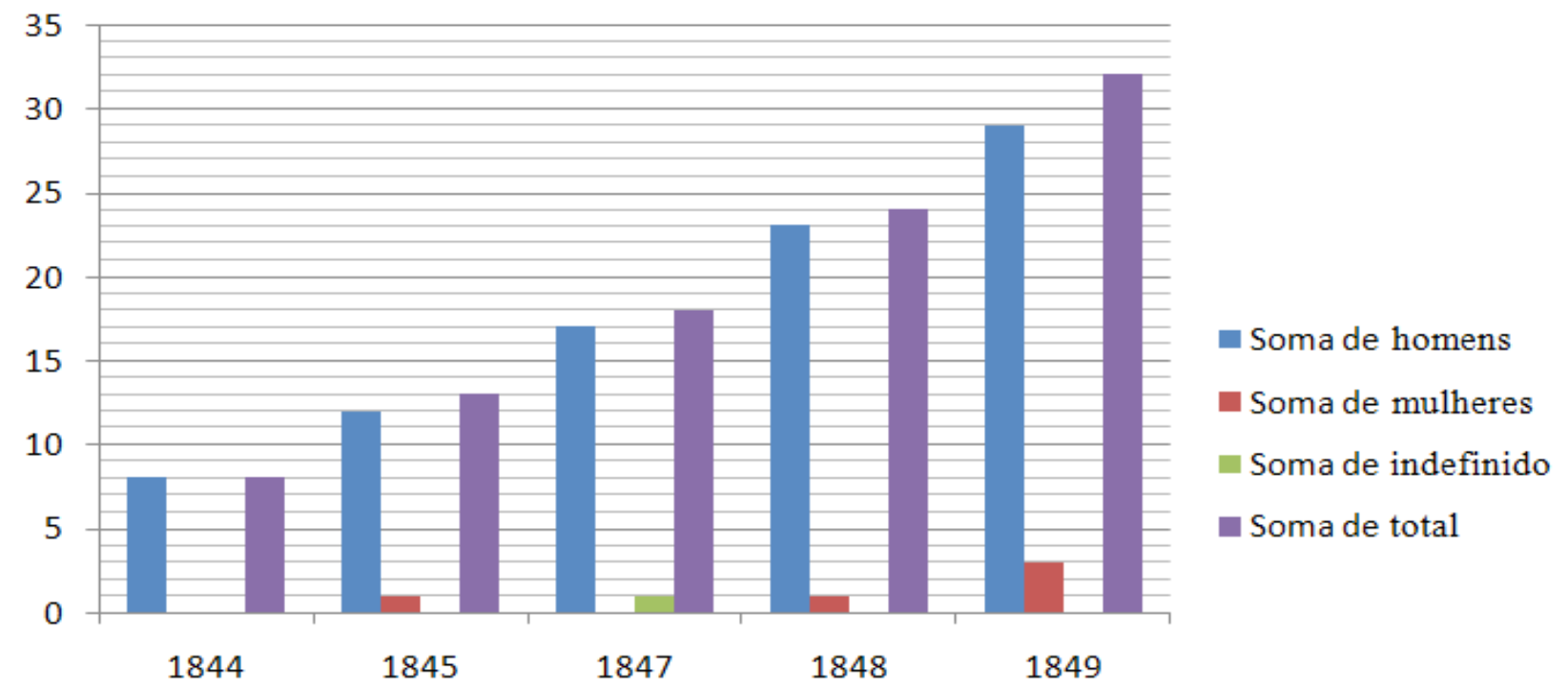

Fonte: Almanak Laemmert

No Gráfico 1, a divisão é feita por ano e gênero masculino e feminino. Aparece um gênero indefinido no ano de 1847, o qual optou-se por manter separado. Nesse gráfico também percebe-se um gradativo aumento no número de anúncios voltados ao ensino musical por ano.

5 Este periódico surgiu em $1^{\circ}$ de outubro de 1827 por Pierre Plancher (1779-1844) e divulgava informações sobre a política, economia, relações exteriores, espaços de sociabilidade e anúncios de particulares. As transcrições feitas neste trabalho serão atualizadas conforme a ortografia gramatical portuguesa, mantendo apenas as maiúsculas, minúsculas e normas tipográficas específicas.
Apesar de não obtermos informações sobre o ano de 1846 porque algumas páginas não estão digitalizadas, supôs-se o mesmo aumento gradativo, resultado da comparação de outros anos desse período.

Já ao longo da década de 1850, conforme aparece no Gráfico 2, também tem-se um anúncio de gênero indefinido constatado no ano de 1854, e apesar de o número de anúncios ter aumentado, percebem-se algumas oscilações nessa década. 
Gráfico 2. Anúncio de professores de música (1850-1859).

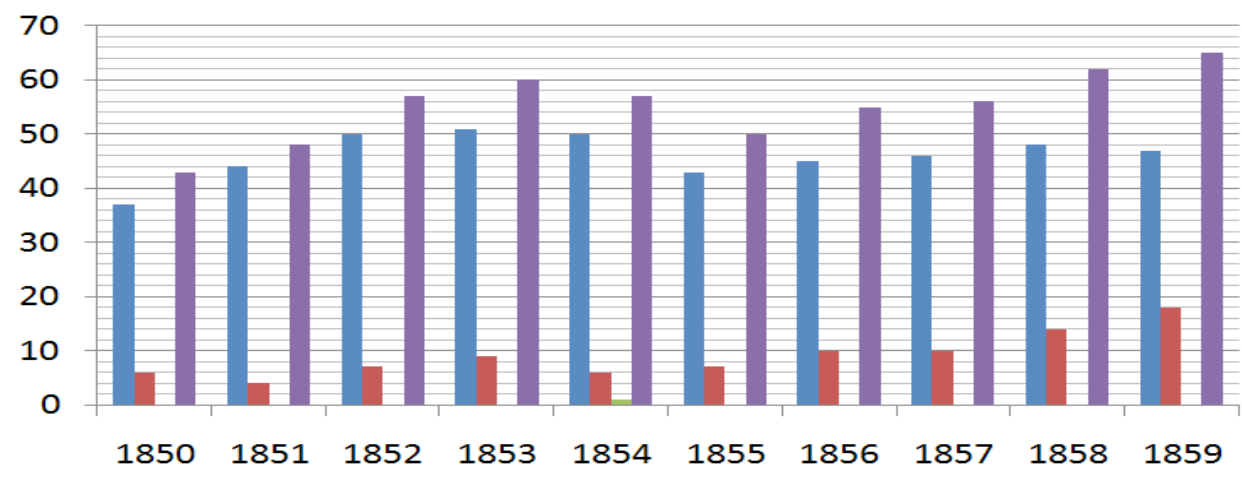

- Soma de homens

- Soma de mulheres

- Soma de indefinido

- Soma de total

Fonte: Almanak Laemmert

As oscilações observadas aconteceram entre 1854 e 1855, retomando o aumento de anúncios nos anos seguintes. Apesar de não ter sido encontrada uma justificativa específica para tais oscilações, que também aconteceram nas décadas de 1860, 1870 e 1880, pode-se supor que: alterações econômicas nesses anos tenham afetado os anúncios, causando sua diminuição; professores tivessem quadros de horários cheios e não tivessem mais tempo para novos alunos; professores deixaram de lecionar; houve falecimentos, mudanças de cidade, de província ou de país. Enfim, várias são as hipóteses que poderiam ter influenciado essas oscilações.

Também é importante observar um aumento no número de professoras no ensino musical. Apesar de quase todas anunciarem ensinar apenas piano e/ ou canto, nos anos de 1857, 1858 e 1859 Francisca Pinheiro de Aguiar divulgou ser professora de piano, canto e flauta, demonstrando existir professoras de outros instrumentos.

A limitação do ensino feminino instrumental de piano podia ser entendida pela conduta social existente no período, uma vez que a prática desse instrumento era comum por limitar os movimentos corporais de suas praticantes e sua execução ser feita sentada, ocultando o corpo dos espectadores (SILVA, 2008).

Dando continuidade aos anúncios impressos no Almanak Laemmert, observa-se, nos Gráficos 3, 4 e 5 referente às décadas de 1860, 1870 e 1880, respectivamente, a continuidade no aumento de anúncios sobre o ensino musical.

Gráfico 3. Anúnci o de professores de música (1860-1869).

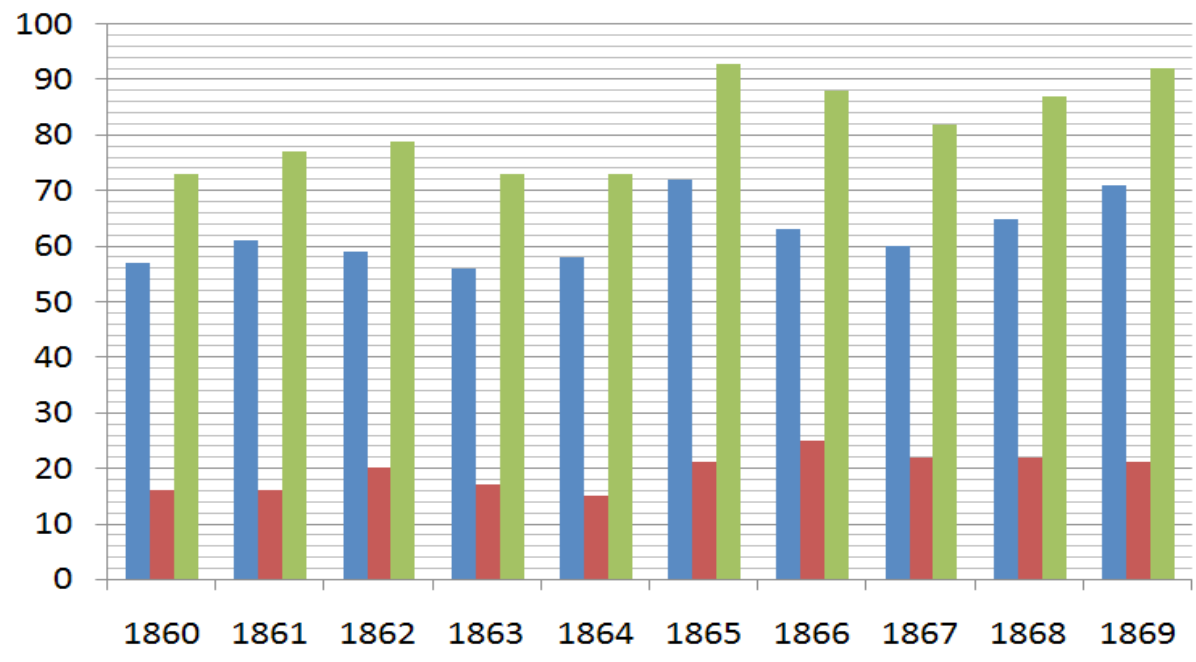

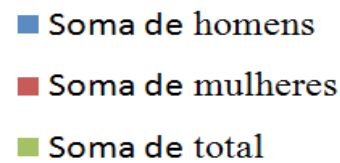

Soma de total

Fonte: Almanak Laemmert 
Gráfico 4. Anúncio de professores de música (1870-1879).

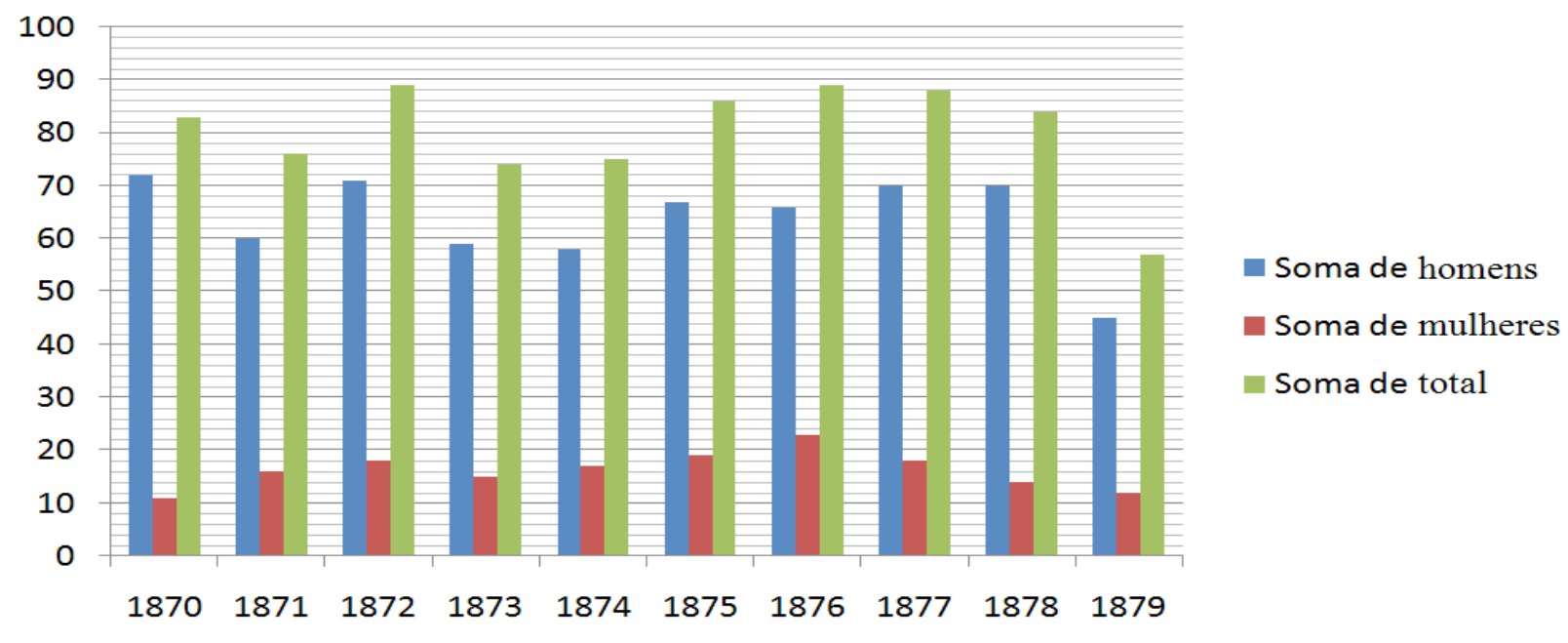

Fonte: Almanak Laemmert

Gráfico 5. Anúncio de professores de música (1880-1889).

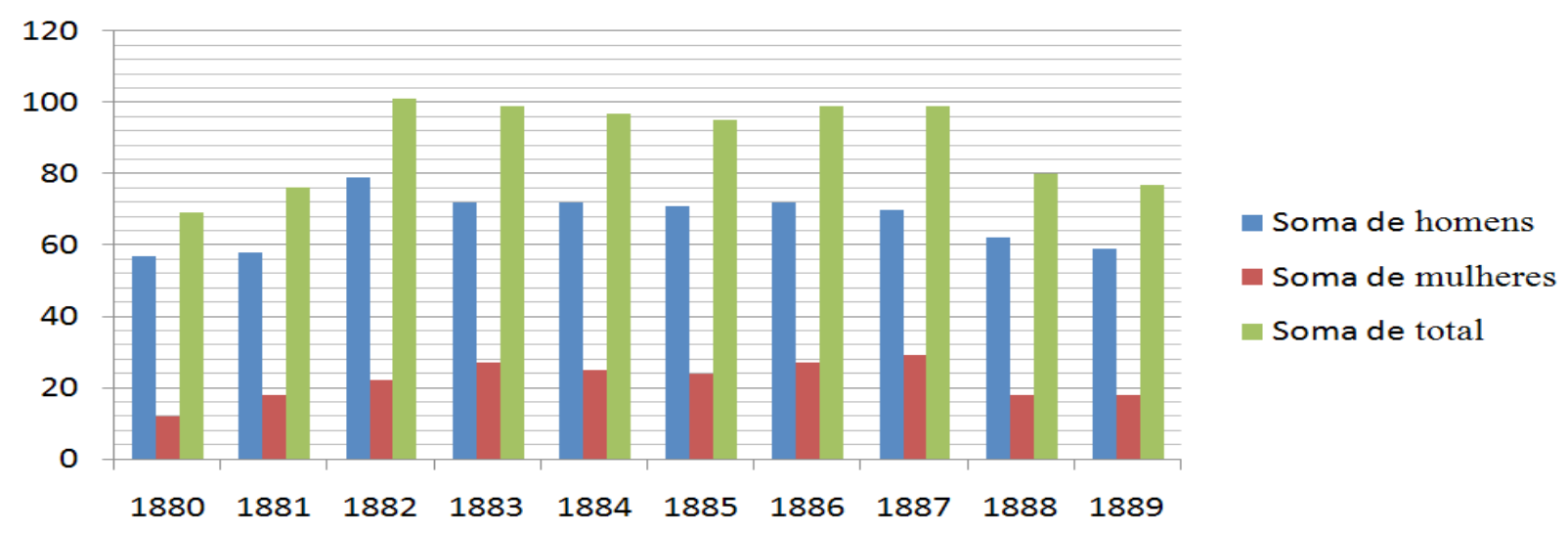

Fonte: Almanak Laemmert

Enquanto na década de 1860 se manteve a média entre setenta anúncios nos cinco primeiros anos, nos cinco últimos houve um aumento para oitenta. Já nas décadas de 1870 e 1880, as oscilações foram constantes, chegando ao número de cinquenta e sete anúncios no ano de 1879, enquanto no ano de 1882 o número quase dobrou, chegando a cento e um.
O aumento no número de avisos de professores de música e suas alterações durante a segunda metade do século XIX também refletiu na crescente oferta de instrumentos ensinados e consequentemente suas oscilações.

Para se ter uma ideia, no Gráfico 6 podem ser observados os instrumentos anunciados e a quantidade de anúncios na década de 1940. 
Gráfico 6. Anúncios de instrumentos ensinados (1844-1849), exceto 1846.

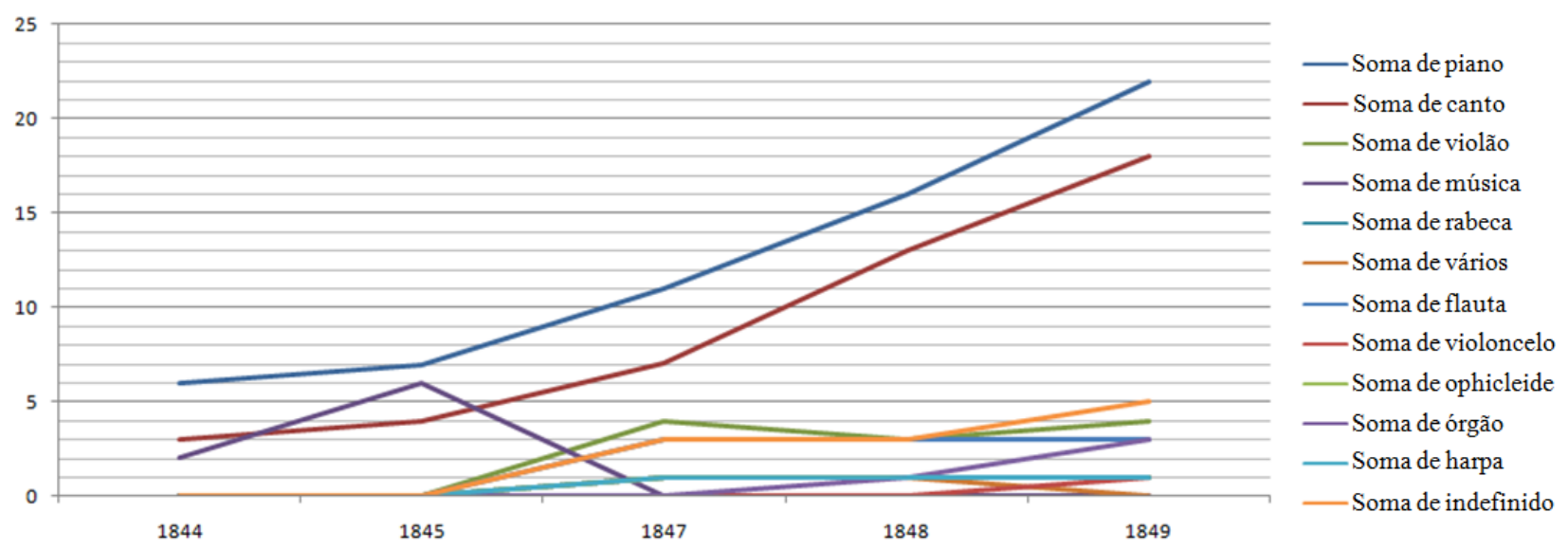

Fonte: Almanak Laemmert

Neste gráfico pode-se observar, além do crescimento no número de anúncios de piano e canto, que permaneceu em grande quantidade durante todas as publicações do Almanak Laemmert, a variedade de instrumentos ensinados no

período, mesmo que eles apareçam poucas vezes ou em menor número.

Outro fato observado foi que, ao comparar anualmente a quantidade de anúncios de professores com a quantidade de instrumentos anunciados, constata-se que o número de instrumentos foi maior, pois muitos professores ensinavam mais de um instrumento, além do local de ensino ser diversificado por toda a cidade do Rio de Janeiro.
Assim, os Gráficos 7, 8, 9 e 10, referentes às décadas de 1850, 1860, 1870 e 1880 respectivamente, representam o aumento e a oscilação de anúncio de instrumentos, assim como visto nos gráficos anteriores indicando a quantidade de professores.

Gráfico 7. Anúncios de instrumentos ensinados (1850-1859).

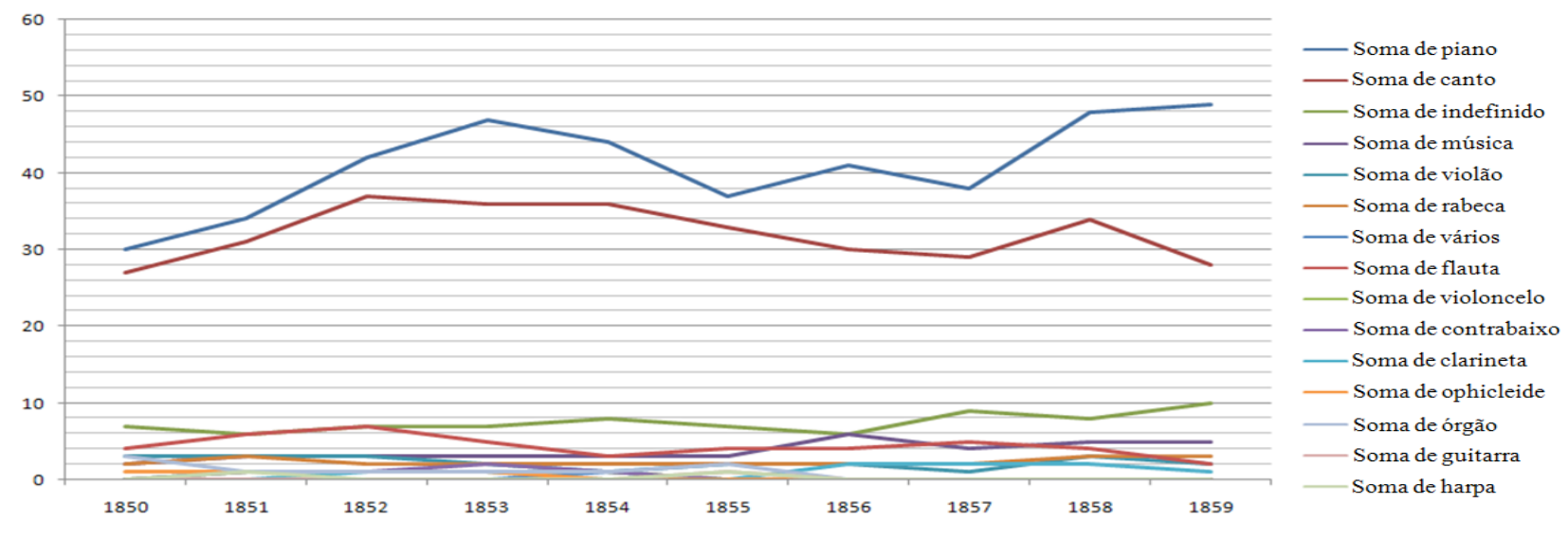

Fonte: Almanak Laemmert 
Gráfico 8. Anúncios de instrumentos ensinados (1860-1869).

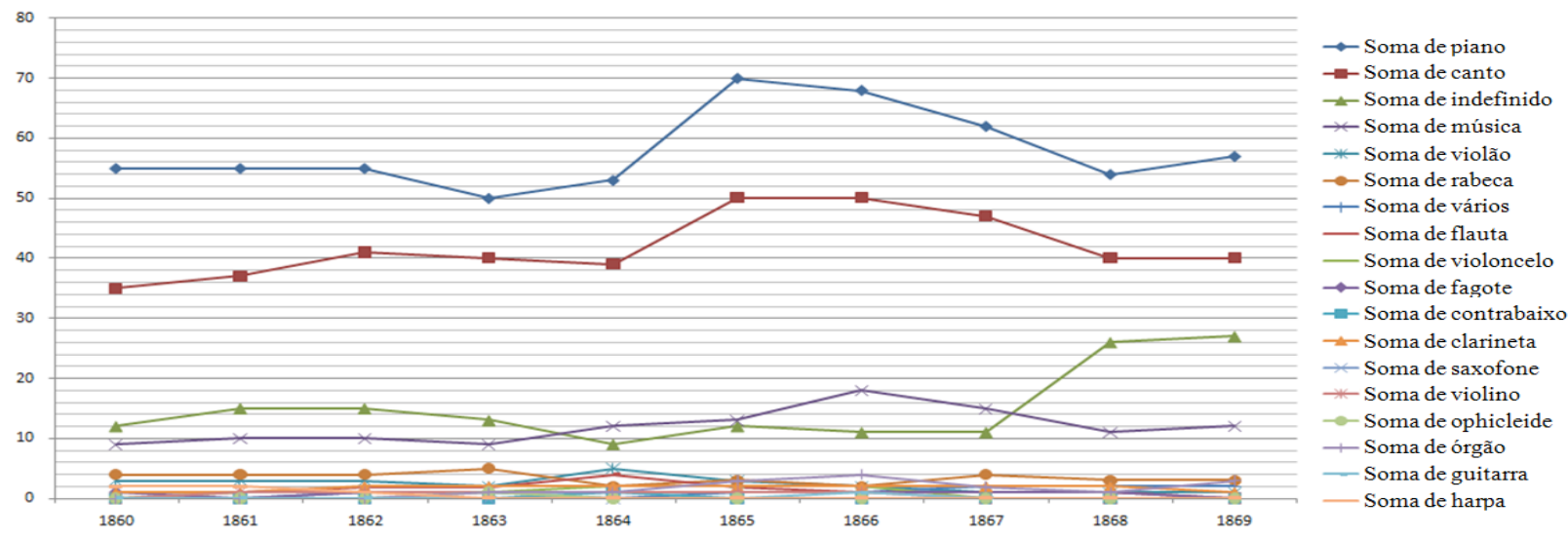

Fonte: Almanak Laemmert

No Gráfico 7 identificou-se o aparecimento de avisos voltados ao ensino do contrabaixo, da clarineta e da guitarra, enquanto no Gráfico 8 surgiram anúncios voltados ao ensino do violino e do fagote.

Comparando os dois gráficos, percebe-se que o número de anúncios de professores de piano e canto são maiores que os avisos de outros instrumentos, além de ser observado um leve aumento no número de anúncios de instrumentos indefinidos. Esse aumento e algumas oscilações podem ser constatados nos Gráficos 9 e 10, ultrapassando as publicações de professores de canto em alguns anos:

Gráfico 9. Anúncios de instrumentos ensinados (1870-1879).

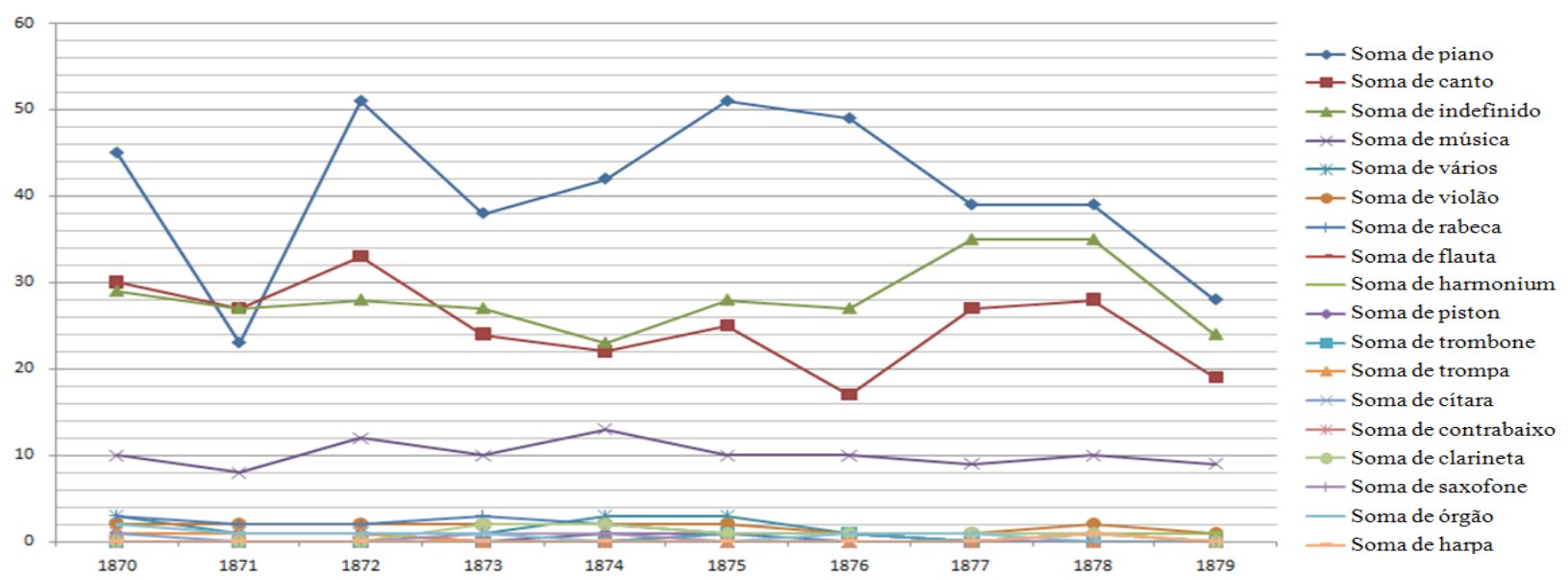

Fonte: Almanak Laemmert 
Gráfico 10. Anúncios de instrumentos ensinados (1880-1889).

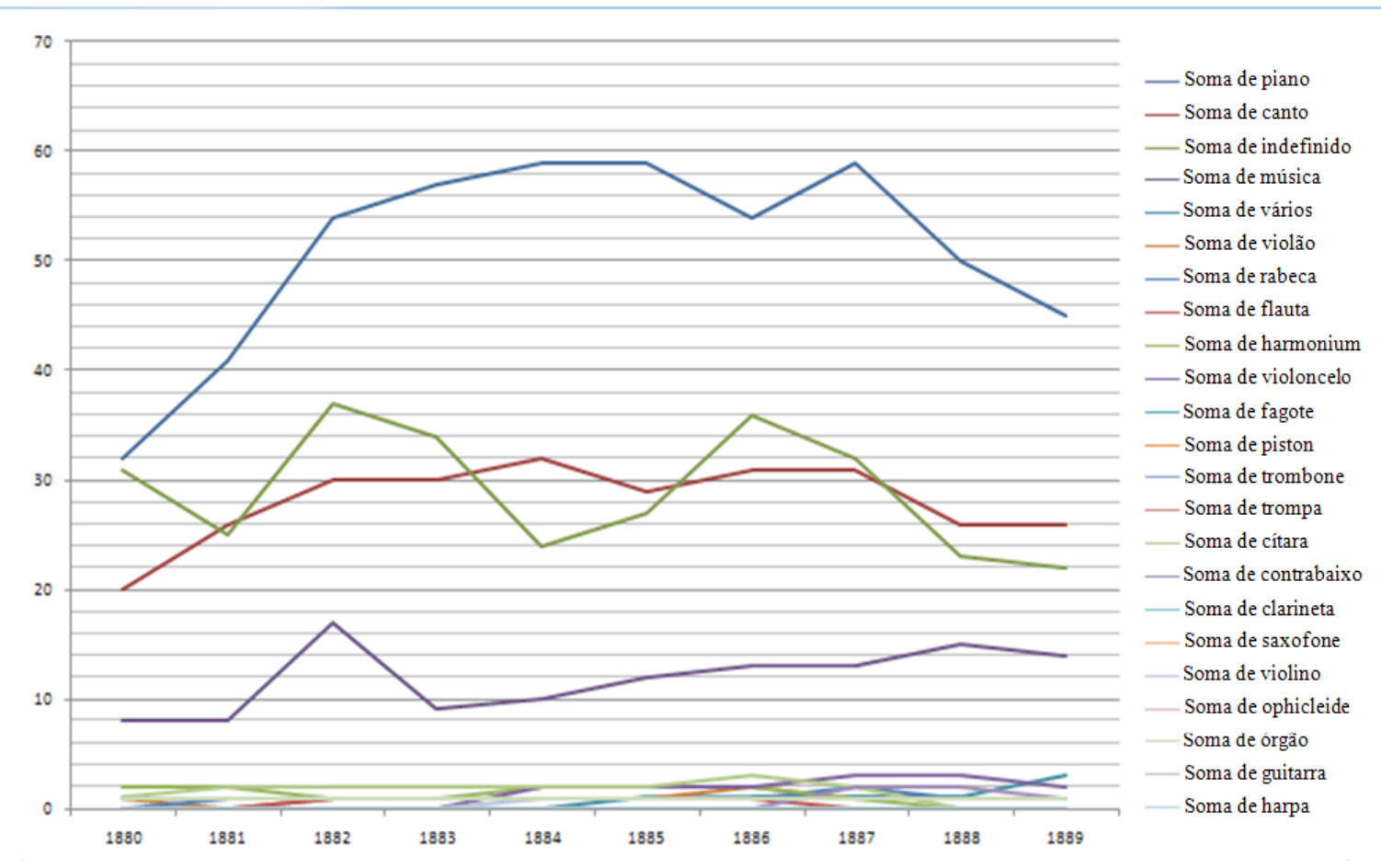

Fonte: Almanak Laemmert

O aumento e as oscilações nas publicações de instrumentos indefinidos podem ser justificadas pelo fato de esses professores já terem anunciado, em anos anteriores, os instrumentos que ensinavam, ao mesmo tempo que poupariam dinheiro com novos avisos, uma vez que o periódico cobrava mil réis por linha utilizada. Assim, percebe-se que o aumento no número de anúncios no Almanak Laemmert identificava apenas o nome e o endereço do(a) professor(a).

Já o valor cobrado pelo ensino musical raramente era anunciado nesse periódico. Das poucas informações encontradas, em 1865 D. Leopoldina de Souza apareceu cobrando mil réis pelo ensino do piano ${ }^{6}$. Em 1874, Izidoro Antonio Terra, professor de qualquer instrumento, cobrou "uma jóia de vinte mil réis no ato de inscrever-se, e cinco mil réis por cada dez lições por mês, lições avulsas dois mil réis cada uma"7.

6 Almanak Laemmert. Rio de Janeiro: Tipografia Universal de Laemmert, 1865, p. 482. Disponível em: <http://brazil.crl.edu/bsd/bsd/almanak/al1865/00000488.html>. Acesso em 21 jan. 2016.

7 Almanak Laemmert. Rio de Janeiro: Tipografia Universal de Laemmert, 1874, p. 596. Disponível em <http://brazil.crl.edu/bsd/bsd/almanak/al1874/00000605.html>. Acesso em 21 jan. 2016.
Enquanto isso, O fornal do Commercio manteve mais anúncios musicais indicando valores, desde métodos de ensino, de partituras, de aluguéis ou vendas de instrumentos a custos do ensino musical por professores:

Método para se aprender a tocas bem flauta.

Este método se compõe dos dois primeiros livros do método de Berbiguer, traduzidos do francês, seguidos de uma coleção de hinos, modinhas, valsas, etc., formando tudo 74 páginas de impressão; preço $6 \$ 000$ réis. Acha-se também reimpresso o Compendio de Música por Francisco Manoel da Silva, para uso dos alunos do Imperial colégio de Pedro Segundo, contento todos os princípios elementares da música; preço $1 \$ 000$ réis. Vende-se na imprensa de música de P. Laforge, rua da Cadeia, n. 89. (JORNAL DO COMMERCIO, 11 jan. 1839, p. 04).

Com grandes oscilações nos valores de partituras, métodos de ensino e instrumentos musicais, supõe-se não haver um padrão no custo desse ensino, uma vez que não havia legislação específica no período para regular esse comércio.

Já que não havia uma regulamentação, muitos músicos buscavam anunciar em impressos periódicos sua fonte de sustento, tanto que alguns professores apareceram 
em mais de um periódico, como o caso de Geraldo Antonio Horta, Francisco Sá Noronha e José Fachinetti.

O professor Geraldo Antonio Horta foi anunciado entre os anos de 1854 a 1858 no Almanak Laemmert (LAEMMERT, 1854, p. 384; 1855, p. 420; 1856, p. 448; 1857, p. 480; 1858, p. 489), e teve uma partitura de quadrilha de contradanças, intitulada "Sonho das fadas", impresso no O fornal das Senhoras com duas páginas na $123^{\mathrm{a}}$ edição, 7 de maio de 1854, e por conta de um erro na impressão, as três folhas restantes foram impressas na 124ª edição, 14 de maio de 1854.

Neste periódico, dirigido inicialmente pela argentina Joanna Paula Manso de Noronha (1819-1875), algumas partituras acompanhavam o impresso, e em algumas edições apareciam anúncios ou comentários sobre professores de piano e/ou canto. Dentre eles, ganharam destaque às partituras do violonista Francisco Sá Noronha (esposo da redatora-chefe) e do músico José Fachinetti.

Francisco Sá Noronha teve sete partituras impressas no primeiro semestre de 1852 no O fornal das Senhoras, mesmo período de direção de sua esposa, e uma partitura impressa no início de 1853. Além disso, ele apareceu no Almanak Laemmert em 1852 como mestre de canto no teatro de São Januário, já que o teatro de São Pedro, no qual ele atuava, estava passando por reformas devido a um incêndio no mesmo ano (LAEMMERT, 1852, p. 287).

José Fachinetti, que foi anunciado como professor de piano e canto no O fornal das Senhoras, anunciou seu romance no fornal do Commercio por 320 réis, vendido na imprensa de música de Pierre Laforge, na Rua da Cadeia, número 89 (JORNAL DO COMMERCIO, 1841).

Tais anúncios denotam como alguns redatores inseriam as partituras musicais para angariar mais assinantes em seus periódicos.

Além de Joanna Paula Manso de Noronha, Francisco de Paula Brito (1809-1861) também inseriu partituras em algumas edições de seu periódico $A$ marmota na corte (1849-1852). Em um anúncio, publicado na $226^{a}$ edição, "todas as pessoas que assinarem a Marmota no presente semestre (janeiro a junho), receberão do presente a - VALSA PULADA - que se vende a $1 \$ 000$ rs., na loja desta tipografia, e foi distribuída grátis entre os assinantes antigos (BRITO, 1852, p. 4).

Desse modo, é possível perceber que alguns redatores inseriam partituras musicais em determinadas edições como uma estratégia para a compra do periódico por meio das assinaturas, além de contribuírem na visibilidade e na ampliação dos professores e professoras de música no Rio de Janeiro.

Com o aumento na demanda pelo ensino de música, de professores e de instrumentos, surgiram outros periódicos voltados a essa prática tanto no Rio de Janeiro como em outras regiões do país: "PhiloHarmonico, Periodico Muzical (1842), Ramalhete das Damas (1842-1850) e O Brasil Musical (1848-1875), impressos no Rio de Janeiro; Recreio das jovens pianistas (1857 a 1859), em Salvador; Lyra Rio-Grandense - Álbum Musical (c. 1876-c.1886), em Porto Alegre", e aqueles impressos na França e importados: "L'Art Musical, Fournal de Musique, Le Conseiller des Dames et des Demoiselles, Fournal des Demoiselles, Piano-Revue: Les chefs d'oenvre du piano" (ZAMITH, 2011, p. 20).

Por fim, todas as informações elencadas permitem que se observe o crescimento que o ensino musical teve ao longo do reinado de D. Pedro II. Os anúncios em impressos periódicos tiveram grande importância na visualização e ampliação desse espaço, bem como legitimam o ensino musical no Rio de Janeiro e em todo o país.

\section{CONSIDERAÇÕES FINAIS}

Foi possível elencar, nesta pesquisa, a quantidade de anúncios musicais divulgados no Almanak Laemmert (1840-1889), com exceção do ano de 1846, por suas páginas não estarem disponíveis pela microfilmagem e nem digitalizadas.

Nesses anúncios, constatou-se que a grande maioria de professores eram homens. Porém, a presença feminina, ainda que menor, foi constante durante praticamente todos os anos de publicação.

Ainda que o ensino musical feminino estivesse restrito ao piano e ao canto, constatou-se que uma professora de flauta era anunciante, demonstrando que essa norma social não era seguida por todas as mulheres.

Quanto aos instrumentos divulgados, observou-se um grande número de anúncios de piano, seguidos pelo canto e, posteriormente, variando entre anúncios de instrumentos indefinidos e outros em menor escala. Supôs-se que a falta de definição do instrumento ensinado estivesse motivada por esse(a) professor(a) já ser conhecido(a) pelos leitores do periódico, e/ou por questões econômicas, uma vez que o custo para divulgar no jornal era cobrado por linha. 
A respeito do valor do ensino musical, provavelmente podia variar conforme o professor, o instrumento, o horário e outras questões ainda não levantadas, porém percebeu-se não haver um padrão de preço, uma vez que não existiam leis que regulamentassem a profissão de professor de música.

Por fim, a variedade de instrumentos ensinados foi uma constante em todo o período, demonstrando que o Rio de Janeiro não era só uma "cidade dos pianos", conforme comentou Araújo Porto-Alegre, em 1856 (ANDRADE, 1967), mas de múltiplas sonoridades e práticas musicais. A visibilidade desta multiplicidade e sua importância continuarão a ser pesquisadas, objetivando um maior e melhor conhecimento de nossa história musical por anúncios em impressos periódicos durante o segundo reinado.

\section{REFERÊNCIAS}

ABREU, M. Duzentos anos: os primeiros livros brasileiros. In: BRAGANÇA, A.; ABREU, M. (Orgs.). Impresso no Brasil: dois séculos de livros brasileiros. São Paulo: Unesp, 2010.

ANDRADE, M. Pequena história da música. São Paulo: Livraria Martins Editora, 1967.

BARBOSA, E. V.; CUNHA, F. L. O ensino musical no reino de D. Pedro II através de impressos periódicos: (1840-1889). In: SIMPÓSIO INTERNACIONAL PATRIMÔNIOS: CULTURA E SOCIEDADE NO SÉCUlO XXI, 1., 2015, Ourinhos. Anais...
Ourinhos: UNESP/ Câmpus Experimental de Ourinhos, 2015. p. 314-328.

BRITO, F. P. A marmota na corte. Rio de Janeiro: Typographia Dous de Dezembro, 1852.

JORNAL DO GOMMERGIO. Rio de Janeiro: Typographia Imperial e Constitucional de J. Villeneuve e Comp., 1838.

LAEMMERT, E.; LAEMMERT H. Almanak administrativo, mercantil e industrial do Rio de Janeiro. Rio de Janeiro: Typographia Universal de Laemmert, 1844-1889.

LÉRY, J. Histoire d'um voyage fait em la terre du Brésil. $1^{a}$ ed. Chuppin, Antoine - La Rochelle, 1578.

NORONHA, J. P. M.; VELlASCO, V. A. X. B.; NEVES, G. N. P. S. O jornal das senhoras. Rio de Janeiro: Typographia Parisiense, 1852-1855.

SILVA, E. M. A. M. Glara Schumann: compositora x mulher de compositor. 2008. Dissertação (Mestrado em Processo de Criação Musical) - Escola de Comunicações e Artes, Universidade de São Paulo, São Paulo, 2008.

ZAMITH, R. M. B. A dança da quadrilha: da partitura aos espaços festivos: música, dança e sociabilidade no Rio de Janeiro oitocentista. Rio de Janeiro: E-papers, 2011. 